\title{
VALUE OF STOCK LEVEL INFORMATION AND IMPACT ON MANUFACTURERS' SUBSTITUTION DECISIONS
}

In this work, we study the product substitution decisions of a manufacturer that produces multiple items. We first quantify the cost savings due to flexibility attained through substitution. Ideally, the manufacturer must use the stock level information when giving production, scheduling and substitution decisions. In practice however, such decisions are often given ignoring the available information. In this work, we also address the importance of using stock level information by quantifying its value. Results show that using stock level information is critical especially when taking production scheduling decisions.

Keywords: Product substitution, production scheduling, value of information, stochastic control of queues.

\section{Introduction}

In operations management, substitution is the practice of meeting the demand for an item with an alternative item. In general, substitution can take place at the product (end-item) level or at the component level, can be static (anticipative) or dynamic (stockout-based). Practice of product substitution can be observed in various sectors, such as computer manufacturing, [1], semi-conductor manufacturing [2], in aluminum or steel industry [3] and [4]. A common assumption is that the products can be ordered from uppergrade to lower-grade and it is possible to substitute a lowergrade item with an upper-grade item. This practice is called one-way substitution. In this study, we assume the items are not necessarily ordered in grade, in other words, they are equivalent, but there is a cost and time associated with the substitution process.

In the literature, there exists a body of work on manufacturerdriven substitution. The demand is either assumed deterministic and the problem is modeled as a lot-sizing problem with substitution, or the demand is assumed stochastic, but when determining the substitution policy dynamic stock level changes are not taken into consideration. The only exception is the recent work by [5], where substitution and production scheduling decisions are made dynamically. In [5] the authors study the effect of flexibility of the manufacturing process on certain performance measures, whereas in our study we quantify the value of information and the cost savings due to substitution. Manufacturer-driven substitution problems are similar to the part transshipment problems in logistics networks. In the literature on transshipments, many of the studies do not take stock level information at the locations into consideration when determining the transshipment and the replenishment policies, but resort to approximate approaches. A few studies that take stock level information into consideration are [6], [7], [8], [9]. This study aims to contribute to that line of research as well.
In the following, we introduce the problem setting and state the corresponding optimization model. We characterize the optimal operating policy under the assumption that the manufacturer uses perfect stock level information. Then, through numerical analysis we quantify the savings due to substitution, and the value of stock level information.

\section{The problem setting and the model}

The manufacturer produces two products (items), $N=\{1,2\}$. Demand for each product $i \in N$, arrives independently with rate $\lambda_{i}$ following a Poisson process. The products are stored separately, but they are produced by a single production facility one unit at a time. The production rate is $\mu$ for both products. Production times are exponentially distributed random variables. Switching from one product to the other is assumed to take no time or money. Upon demand arrival for a certain product, if the product is available in the stock, the demand is immediately met. Otherwise, the demand is either backlogged, or is met by the substitute product. The substitution of product $j$ with product $i$ requires processing on product $i$ and thus is assumed to take an expected time of $1 / \mu_{s}$. The substitution times are exponentially distributed random variables. It is assumed that the manufacturer may substitute product $j$ with product $i$ before the demand is realized as an hedge against risk of product $i$ stock-out. At a given time a product may be processed to substitute only one other product. In other words, for each product the substitution occurs one at a time. For each item i kept in stock a cost of $h_{i}$, and for each backordered demand of product $i$ a unit cost of $b_{i}$ is incurred per unit time. The cost of substituting product $j$ with product $i$ is $c_{i j}$. It is assumed that one unit of product $i$ substitutes one unit of product $j$.

The system state is denoted with $X(t)=\left(X_{1}(t), X_{2}(t)\right)$, where $X_{i}(t)$ denotes the net inventory level for product $i$ at time $t$. The

\footnotetext{
* Nursen Tore, Secil Savasaneril, Yasemin Serin

Department of Industrial Engineering, Middle East Technical University, Ankara, Turkey, E-mail: ssecil@metu.edu.tr
} 
manufacturer decides which item to schedule, and whether to substitute product $j$ with product $i$. We assume that the production and the substitution decisions can be cancelled at any time (e.g., upon a state change), given that the process is not completed. Thus, production, scheduling, and substitution decisions can be taken at any point in time. The production scheduling decision is whether to produce or not, and which item to produce. The substitution decision for the substitute item $i$ is, which item should be substituted by $i$. The substitution decision is taken only if $X_{i}(t)>0$. However, net inventory level of item $j$ to be substituted, $X_{j}(t)$, can possibly be positive. Decisions regarding production are either to stop production, or to produce product 1 or product 2 . The substitution decision implies either no substitution takes place, product 1 is substituted with product 2 or vice versa. Because the system has memoryless property(i.e., due to Poisson arrivals, and exponential production and substitution times), the optimal policy is a state dependent Markovian policy. Thus we omit the index $\mathrm{t}$ and denote the state with net inventory level in the system $x=\left(x_{1}, \cdots, x_{n}\right)$.

The objective is to minimize the sum of holding, backorder and substitution costs, and the problem is an optimal control problem that can be modeled as a Markov decision process (MDP). In state $x$, the cost is incurred at rate $c(x)=h_{1} x_{1}{ }^{+}+b_{1} x_{1}{ }^{-}+h_{2} x_{2}{ }^{+}+$ $b_{2} x_{2}{ }^{-}$.

Average cost criterion is used to determine the optimal policy. Let the uniform rate be $\Lambda=\lambda_{1}+\lambda_{2}+\mu+\mu_{s}$. The functional equation is expressed as follows:

$$
\begin{aligned}
& v\left(x_{1}, x_{2}\right)+g / \Lambda=1 / \Lambda\left(c(x)+\lambda_{1} v\left(x_{1}-1, x_{2}\right)+\right. \\
& \left.+\lambda_{2} v\left(x_{1}, x_{2}-1\right)+\mu \emptyset_{1} v\left(x_{1}, x_{2}\right)+\mu_{s} \emptyset_{2} v\left(x_{1}, x_{2}\right)\right)
\end{aligned}
$$

where $c(x)=\sum_{i \in\{1,2\}} h_{i} x_{i}^{+}+b_{i} x_{i}^{-}, \emptyset_{1}$ is the replenishment operator, and $\emptyset_{2}$ is the substitution operator. The operators are defined on real-valued functions as follows,

$$
\begin{aligned}
& \emptyset_{1} v\left(x_{1}, x_{2}\right)=\min \left\{v\left(x_{1}+1, x_{2}\right), v\left(x_{1}, x_{2}+1\right),\right. \\
& \left.v\left(x_{1}, x_{2}\right)\right\} \\
& \emptyset_{2} v\left(x_{1}, x_{2}\right)=\min \left\{v\left(x_{1}, x_{2}\right), v\left(x_{1}-1, x_{2}+1\right)+\right. \\
& \left.+c_{12}, v\left(x_{1}+1, x_{2}-1\right)+c_{21}\right\}
\end{aligned}
$$
1.

We characterize the structure of the optimal policy in Theorem

Theorem 1 The optimal policy can be characterized by idling, production switchover and substitution threshold functions. There exist $S_{1}\left(x_{2}\right), K_{1}\left(x_{2}\right), T_{1}\left(x_{2}\right)$, and their respective counterparts; where $S_{1}\left(x_{2}\right)$ is the threshold for $x_{1}$ for a given $x_{2}$, below which it is more profitable to produce product 1 than not to produce it. Also, $K_{1}\left(x_{2}\right)$ is the production switchover threshold for $x_{1}$ for a given $x_{2}$ below which it is more profitable to produce product 1 than to produce product 2 , and above which reverse is true; $T_{1}\left(x_{2}\right)$ is the substitution threshold for $x_{1}$ for a given $x_{2}$ below which substituting product 2 with product 1 is more profitable than not substituting, and above which substituting product 2 with product 1 is not beneficial.

\section{Furthermore, the following hold:}

1. $S_{1}\left(x_{2}\right)$ is decreasing with $x_{2}$.

2. The decrease in $S_{1}\left(x_{2}\right)$ occurs in one-step jumps in the sense that one unit of increase in $x_{2}$ results in at most one unit of decrease in $S_{1}\left(x_{2}\right)$.

3. $K_{1}\left(x_{2}\right)$ and $T_{1}\left(x_{2}\right)$ are increasing with $x_{2}$.

The same properties hold for their respective counterparts.

Proof. See Appendix.

The structure implies that the production policy is to produce if $x_{1}<S_{1}\left(x_{2}\right)$ or $x_{2}<S_{2}\left(x_{1}\right)$. If production takes place, and if $x_{1}$ is less than $K_{2}\left(x_{2}\right)$, then product 1 is produced.

The substitution policy is if $x_{1}$ is greater than $T_{1}\left(x_{2}\right)$, then substitute product 2 with product 1 to balance the inventory levels and the risks. Note that the higher the rate of substitution, the lower the level at which the substitution requirement occurs. The intersection of the switching curve $\left(K_{1}\left(x_{2}\right)\right)$ with idling curves $\left(S_{1}\left(x_{2}\right)\right.$ and $\left.S_{2}\left(x_{1}\right)\right)$ defines a hedging point. The hedging point $\left(S_{1}, S_{2}\right)$ is the base stock level. In other words, for every state that satisfies $\left(x_{1}, x_{2}\right)<\left(S_{1}, S_{2}\right)$, the production action is taken. Under the average reward criteria, any state that doesn't satisfy $\left(x_{1}, x_{2}\right)<\left(S_{1}, S_{2}\right)$ is a transient state. In Fig. 1, the structure of the optimal policy is presented (where $b_{1}>b_{2}$ ).

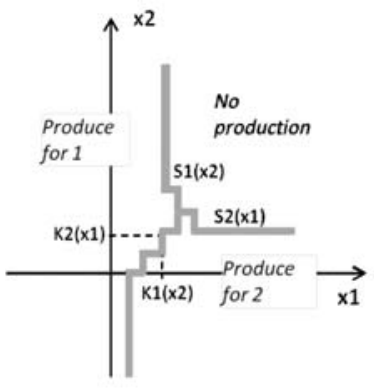

(a) Production scheduling under the optimal policy.

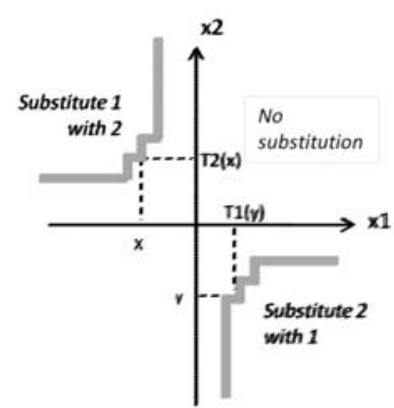

(b) Product substitution decisions under the optimal policy
Fig. 1 Characterization of optimal policy (where $b_{1}>b_{2}$ )

\section{Numerical analysis}

We analyze the impact of production scheduling and substitution decisions on certain performance measures. The optimal policy that is characterized in Theorem 1 fully uses the state information when taking production and substitution decisions. In other words, the production and substitution decisions might change depending on the system status. To quantify the value of state information, 
the optimal policy is contrasted with policies that partially use the state information, namely static production or substitution policies. We define three static policies depending on whether production or substitution uses state information: (i) Dynamic production and static substitution, (ii) Static production and dynamic substitution, (iii) Static production and static substitution, (iv) Dynamic production and no substitution, and (v) Static production and no substitution. Let the average cost figures obtained under these policies be denoted with the corresponding number, for instance, cost under Case (iv) be denoted with Cost $_{i v}$.

Under static production policy, the production scheduling decisions are taken under a "randomized" scheme. In other words, given that $\left(x_{1}, x_{2}\right)<\left(S_{1}, S_{2}\right)$, which item to produce next is selected randomly. Production continues under a randomized scheme until the net inventory level of a product reaches its basestock level. This implies, each product is managed independently without taking into account the net inventory level of the other product. Thus, the state level information is only partially used. Under randomized production the production capacity is allocated in proportion to the arrival rate of the demand for the products. The production rates are independent of the state (unless a basestock level is hit). Note that if the substitution does not exist, the randomized production scheme closely approximates a system where each product is managed as an independent $M / M / 1$ queue. The only slight difference is that when a product is at its base-stock level, the capacity is fully dedicated to the other product.

Under static substitution policy, we assume that the substitution takes place when the inventory level of a substituting product is higher than a constant level, and a substituted product has a negative inventory level. So the substitution decision is given only based on a static level, regardless of the inventory level of the product tobe-substituted. Under static production and static substitution, the decision variables are basestock levels $\left(S_{1}, S_{2}\right)$ and the substitution levels, $\left(K_{1}, K_{2}\right)$. The values are determined optimally by exhaustive search over the state space. If either production or substitution decisions are given dynamically, then the dynamic policy is obtained optimally for given static levels.

We present the findings of the numerical analysis in the following: we assume the products are identical in terms of cost values and production rates, as follows: $\mu=1, \mu_{s}=10$, the substitution cost is $c_{s}=15$, holding costs are $h_{1}=h_{2}=3$, and backordering costs are $b_{1}=b_{2} \in\{10,35,80,125,150,200\}$. For the identical product setting arrival rates are $\lambda_{1}=\lambda_{2} \in[0.05,0.1$, $0.15, \cdots, 0.4\}$, and for the non-identical setting arrival rates are $\lambda_{1}, \lambda_{2} \in\{0.05,0.1, \cdots, 0.4\}$ where $\lambda_{1}+\lambda_{2} \in 0.8$. We would like to note that, since the computational time is affected by the size of the state space, we truncate the state space when evaluating a policy or determining the optimal policy. The size of the state space is $65 \times 65$ where for each dimension 20 is the space allocated for positive values and 45 is the space allocated for negative values.

Observation 1 When products are identical, under static production the cost savings due to substitution is higher than the savings due to substitution under dynamic production, especially under high traffic.

We analyze the cost savings due to substitution under dynamic and static optimal production policies. For this purpose, the following performance measures are defined.

\section{\%Savings due to substitution under}

dynamic production $=\frac{\text { Cost }_{i v}-\text { Cost }_{\text {opt }}}{\text { Cost }_{i v}} 100 \%$

\% Savings due to substitution under

static production $=\frac{\text { Cost }_{v}-\text { Cost }_{i i}}{\text { Cost }_{v}} 100 \%$

\section{\%Savings due to substitution-} Static Production

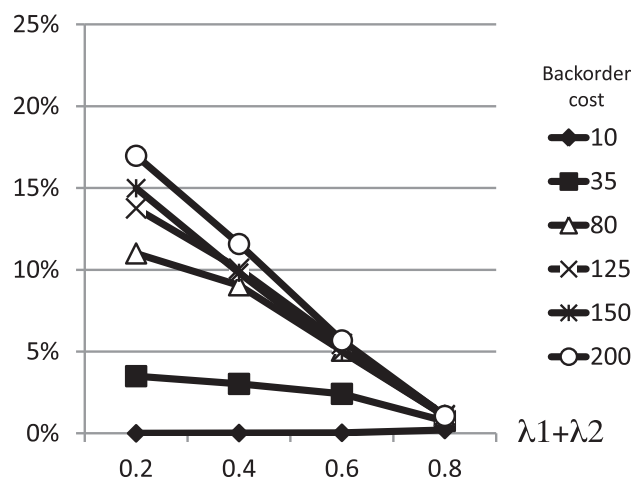

(a)

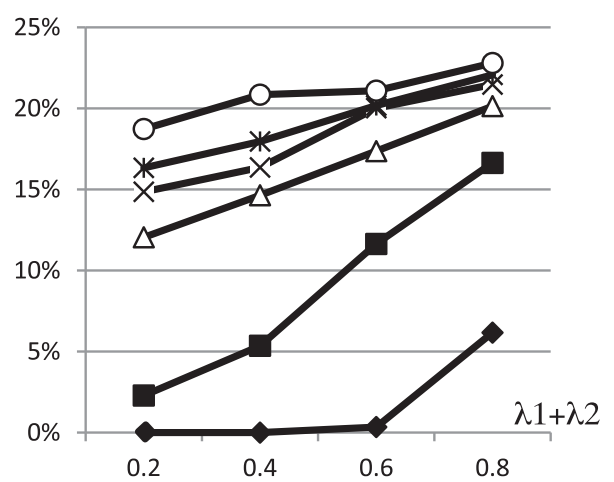

(b)

Fig. 2 Percentage savings due to (dynamic) substitution under production schemes, $\mu_{s}=10, c_{s}=15, \lambda_{1},=\lambda_{2}, h=[1,3,5]$ (results averaged over $h$ ) 
Figure 2 shows that under dynamic production as the traffic intensity increases, the savings due to substitution decreases. On the other hand, under static production, the substitution savings increase with the traffic intensity. This implies that under high traffic intensity the effective usage of the resource gains importance and the dynamic scheduling manages effective usage successfully. The substitution further improves the matching of resource with the need over time. The results show that dynamic scheduling already performs the matching and the need for substitution is minimal. On the other hand, as the traffic intensity increases, the performance of static production deteriorates, and the substitution makes up for the ineffective allocation of the resources over the demand of the products.

We observe that the savings due to substitution increases with an increase in backorder cost. However, for high traffic intensity this may not necessarily be the case under dynamic production. In other words, a change in the backorder level does not impact the benefit of substitution when the traffic intensity is high and the production scheme is dynamic. This implies that the dynamic production can keep the level of backorder under control whereas the static production is not successful at controlling the backorder level, and needs the support of substitution.

Observation 2 As arrival rates become asymmetric under static production the savings due to substitution decreases whereas under dynamic production the savings due to substitution increases.

First of all, it is observed that under both dynamic and static production as products become more asymmetric (in terms of arrival rates) the cost decreases. This can be attributed to the increase in the capacity pooling affect. Furthermore, the percentage savings due tosubstitution under any setting increases with the unit backorder cost, since high backorder cost leads to higher flow due to substitution between the items.
Under dynamic production as products become more asymmetric, the gain due to the substitution increases. When the arrival rate for one of the products is low, the policy tends to lower down the basestock level for that product and meets the demand from inventory of the other product through substitution. As arrival rates become further apart, the flow due to substitution increases. The increase in flow leads to an increase in the savings due to substitution. As shown in Theorem 1, substitution and production scheduling decisions are given under similar dynamics. Thus, the settings that favor dynamic scheduling (i.e., asymmetric arrival rates) also favor the substitution. As a result, we observe an increase in the savings due to substitution whenever the cost under dynamic scheduling decreases (see Fig. 3a). In scalar terms, we observe that as products become similar, the cost reduction due to substitution decreases.

In the case of static production (randomized policy), we observe a reverse situation. The savings due to substitution decreases as the products become more dissimilar. Under unequal arrival rates, both the basestock levels and the capacity allocations are asymmetric under the randomized policy. Thus, the pooling of resources is already achieved due to the asymmetric nature of the arrivals. Actually, under the most asymmetric arrival rates the cost values under dynamic and static production are close to each other. Thus the \% savings due to substitution is also at the same level under the most asymmetric setting. As arrival rates are closer to each other, the performance of the randomized policy deteriorates and dynamic substitution contributes significantly to the pooling of resources. The pooling of resources leads to lower operating cost (see Fig. $3 b)$. Under dynamic production when products are similar the savings due to substitution is limited since the dynamic scheduling achieves resource pooling to a considerable extent.

Observation 3 The savings due to dynamic production scheduling is highest under no substitution. When substitution takes place,

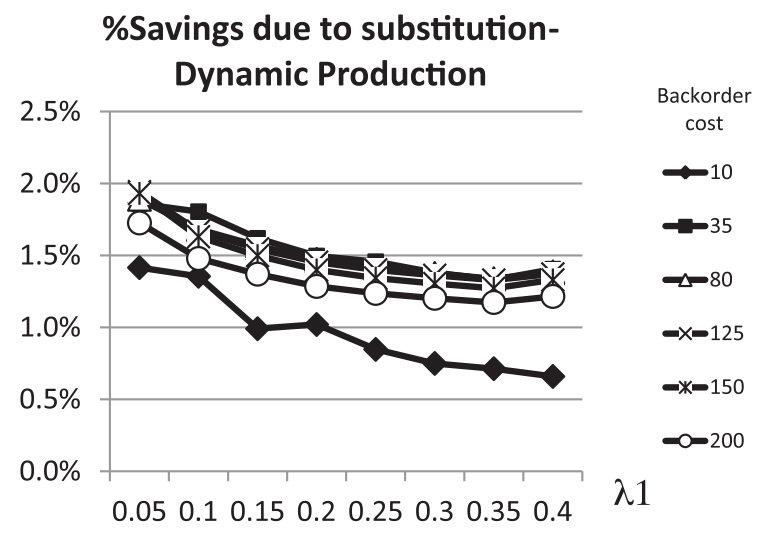

(a)

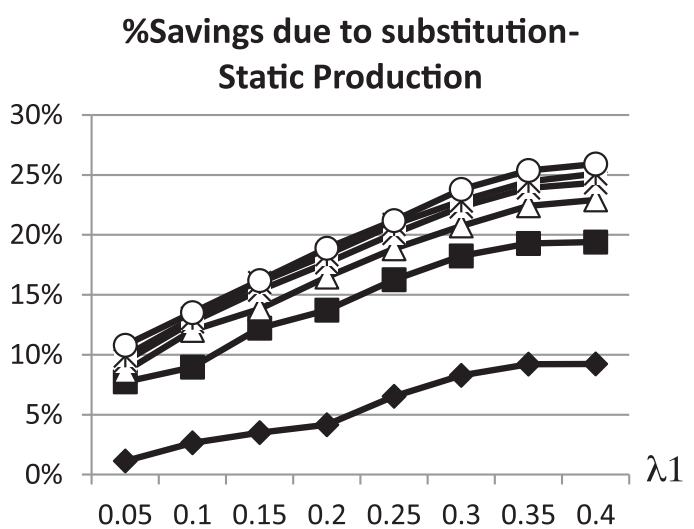

Fig. 3 Savings due to (dynamic) substitution under production schemes when arrival rates are asymmetric $\left(\mu_{s}=10, c_{s}=15, \lambda_{1}+\lambda_{2}=0,8, h=3\right)$ 
the savings due to dynamic scheduling is relatively high under moderate traffic intensities.

To measure the cost savings due to dynamic production, three measures are analyzed,

\%Savings due to dynamic production

under no substitution $=\frac{\text { Cost }_{v}-\text { Cost }_{i v}}{\text { Cost }_{v}} 100 \%$

\% Savings due to dynamic production

under static substitution $=\frac{\text { Cost }_{v}-\text { Cost }_{i v}}{\text { Cost }_{v}} 100 \%$

$\%$ Savings due to dynamic production

under dynamic substitution $=\frac{\text { Cost }_{i i}-\text { Cost }_{\text {opt }}}{\text { Cost }_{i i}} 100 \%$.

As one might expect, the savings due to dynamic production (over static production) is highest under no substitution, and increases with the traffic intensity. Actually, as discussed in Observation 1, dynamic production is more powerful under high traffic intensity. It is further observed that regardless of the substitution cost and rate, the savings due to dynamic production is almost the same under dynamic or static substitution, ie. the savings due to dynamic production does not differ among substitution types (Fig. 4).

In Observation 1 it is stated that the savings due to substitution beyond dynamic production is limited under high traffic intensity. We observe the complement of this observation for dynamic production. Once dynamic substitution (or any form of substitution for that matter) exists, this limits the contribution of dynamic production. Under low arrival rates, the substitution does not take place, and savings due to dynamic production is limited. Under high arrival rates, through the substitution a substantial resource pooling can be achieved, and the additional cost reduction due to dynamic production is limited. For the moderate traffic intensity, dynamic production provides relatively the highest savings (Fig. 4a).

\section{Conclusions}

We study a manufacturer's joint production, scheduling and substitution decisions for two products. The demand is stochastic and all of the decisions are given dynamically under perfect information availability. The optimal policy is characterized as a hedging point, switching curve type policy. Numerical analyses show that the benefit of substitution can be limited when production scheduling is done optimally, especially when the products have similar characteristics. We also look at the impact of availability of stock level information on the production and substitution decisions. Information availability is influencial when making scheduling decisions, whereas its effect is limited on substitution decisions.

\section{Appendix}

Proof of Theorem-1 We characterize the structure of the optimal policy in two steps. In the first step we define a cost-to-go function for $t$ periods, $V^{t}\left(x_{1}, x_{2}\right)$. Using induction we show that $V^{t}\left(x_{1}, x_{2}\right)$ satisfies certain conditions. Then, we show that for the studied problem, an optimal policy exists under the average reward criteria, and that since $V^{t}\left(x_{1}, x_{2}\right)$ satisfies certain conditions the policy can be characterized as in Theorem 1.

Define the $t$ period cost-to-go function as,

$$
\begin{aligned}
& V^{t}\left(x_{1}, x_{2}\right)=\Lambda\left(c(x)+\lambda_{1} V^{t-1}\left(x_{1}-1, x_{2}\right)+\right. \\
& \left.\lambda_{2} V^{t-1}\left(x_{1}, x_{2}-1\right)+\mu \emptyset_{1} V^{t-1}\left(x_{1}, x_{2}\right)+\mu_{s} \emptyset_{2} V^{t-1}\left(x_{1}, x_{2}\right)\right)
\end{aligned}
$$

where $c(x)=\sum_{2} h_{i} x_{i}^{+}+b_{i} x_{i}^{-}, \emptyset_{1}$ and $\emptyset_{2}$ as defined in (2.1) and (2.2).

Let $F$ be the set of real-valued functions, where $f:\left(x_{1}, x_{2}\right) \rightarrow \mathbb{R}$ satisfies the following conditions.

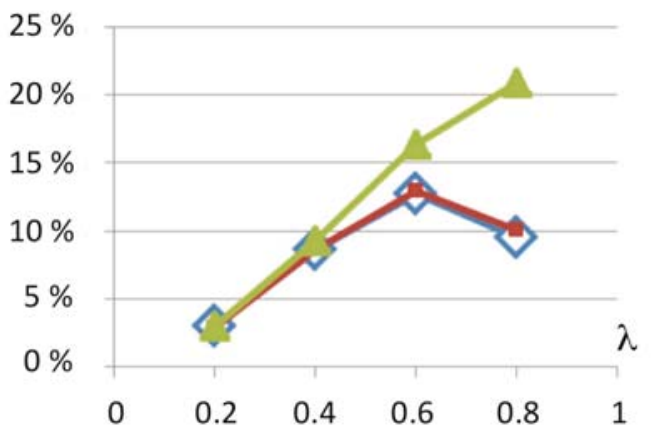

b) $\mu_{s}=1, c_{s}=75$

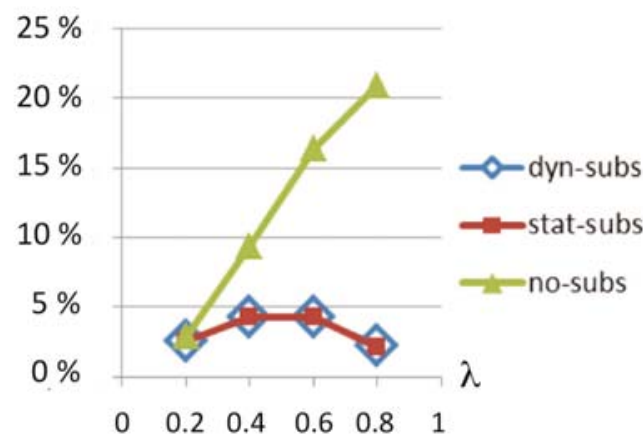

a) $\mu_{s}=10, c_{s}=15$

Fig. 4 Savings due to (dynamic) production under substitution schemes 
$f\left(x_{1}+1, x_{2}\right)-f\left(x_{1}, x_{2}\right) \geq f\left(x_{1}, x_{2}\right)-f\left(x_{1}-1, x_{2}\right)$

$f\left(x_{1}, x_{2}+1\right)-f\left(x_{1}, x_{2}\right) \geq f\left(x_{1}-1, x_{2}+1\right)-$

$-f\left(x_{1}-1, x_{2}\right)$

$f\left(x_{1}+1, x_{2}\right)-f\left(x_{1}, x_{2}+1\right) \geq f\left(x_{1}, x_{2}\right)-$

$-f\left(x_{1}-1, x_{2}+1\right)$

The following conditions are the respective counter parts of (C1)-(C3).

$f\left(x_{1}, x_{2}+1\right)-f\left(x_{1}, x_{2}\right) \geq f\left(x_{1}, x_{2}\right)-f\left(x_{1}, x_{2}-1\right)$

$f\left(x_{1}+1, x_{2}\right)-f\left(x_{1}, x_{2}\right) \geq f\left(x_{1}+1, x_{2}-1\right)-$

$-f\left(x_{1}, x_{2}-1\right)$

$f\left(x_{1}, x_{2}+1\right)-f\left(x_{1}+1, x_{2}\right) \geq f\left(x_{1}, x_{2}\right)-$

$-f\left(x_{1}+1, x_{2}-1\right)$

If $V^{t-1}$ satisfies the conditions $\mathrm{C} 1-\mathrm{C} 6$, then it is possible to infer the following for the decisions made at stage $t$. For a given $x_{2}$, if $V^{t-1}\left(x_{1}+1, x_{2}\right)+V^{t-1}\left(x_{1}, x_{2}\right) \leq 0$, then producing product 1 is preferred to no production. C1 implies when $V^{t-1}\left(x_{1}+1\right)-$ $-V^{t-1}\left(x_{1}\right) \leq 0, V^{t-1}\left(x_{1}\right)-V^{t-1}\left(x_{1}-1\right) \leq 0$ holds, which means if to produce for product 1 is preferred to no production at $\left(x_{1}, x_{2}\right)$, then to produce product 1 is also preferred at $\left(x_{1}-1, x_{2}\right)$. This implies at stage $t$, there exists an inventory level $S_{1}^{t}\left(x_{1}\right)$, below which to produce for product 1 is preferred to no production and above which not to produce is preferred to produce product 1 . In a similar fashion, C4 implies there exists an $S_{2}^{t}\left(x_{1}\right)$.

From C5 it is possible to infer that $S_{2}^{t}\left(x_{2}\right)$ is decreasing in $x_{2}$. The condition states that if for a given $x_{2}$ to produce product 1 is more preferable than not to produce it, then for $x_{2}-1$ to produce product 1 is also preferable. This implies $S_{1}^{t}\left(x_{2}\right) \leq S_{1}^{t}\left(x_{2}-1\right)$.

Conditions $\mathrm{C} 3$ and $\mathrm{C} 6$ together show $K_{1}^{t}\left(x_{1}\right)$ in $x_{2}$. Similarly $K_{2}^{t}\left(x_{1}\right)$ is increasing in $x_{21}$. It is possible to infer from conditions C3) and (C6) also that one unit of increase in $x_{2}$ leads to at most one unit of decrease in $S_{1}^{t}\left(x_{2}\right)$. Same structure holds for $S_{2}^{t}\left(x_{1}\right)$.

Product substitution decisions are also characterized by conditions (C3) and (C6).

For the proof we introduce the following lemma.

Lemma 1 If $V^{t-1} \in F$, then $V^{t} \in F$.

Proof (Lemma-1). In order prove $V^{t} \in F$, it is sufficient to show $\emptyset_{1} V^{t-1}, \emptyset_{2} V^{t-1}$, and $c(x)$ are in $F$. Note that conditions $\mathrm{C} 2$ and $\mathrm{C} 3$ imply $\mathrm{C} 1$. Furthermore, conditions $\mathrm{C} 4-\mathrm{C} 6$ are symmetric to C1-C3. Thus, it is sufficient to show $\emptyset_{1}, \emptyset_{2}$ and $c(x)$ satisfy conditions $\mathrm{C} 2$ and $\mathrm{C} 3$. For simplicity of notation we omit $t-1$ in $V^{t-1}$, and simply denote the $t-1$ period cost-to-go function with $V$. The proof of the lemma is as follows. For operators $\emptyset_{1}$ and $\emptyset_{2}$, and for $c(x)$, it is shown that $\mathrm{C} 2$ and $\mathrm{C} 3$ hold.

\section{Condition C2}

\section{Under production operator, $\emptyset_{1}$}

Let

$$
\begin{aligned}
& w^{1}\left(1, x_{1}, x_{2}\right)=V\left(x_{1}+1, x_{2}\right) \\
& w^{1}\left(0, x_{1}, x_{2}\right)=V\left(x_{1}, x_{2}\right) \\
& w^{1}\left(2, x_{1}, x_{2}\right)=V\left(x_{1}, x_{2}+1\right),
\end{aligned}
$$

then (from 2.1) $\emptyset_{1} V\left(x_{1}, x_{2}\right)=\min _{u \in\{0,1,2\}} w^{1}\left(u, x_{1}, x_{2}\right)$.

We show that $\mathrm{C} 2$ holds,

$$
\begin{aligned}
& \emptyset_{1} V\left(x_{1}, x_{2}+1\right)+\emptyset_{1} V\left(x_{1}-1, x_{2}\right) \geq \\
& \geq \emptyset_{1} V\left(x_{1}, x_{2}\right)+\emptyset_{1} V\left(x_{1}-1, x_{2}+1\right) .
\end{aligned}
$$

Let $u_{1}, u_{2} \in\{0,1,2]$ denote the optimal production action taken in stage $t$ under $\left(x_{1}, x_{2}+1\right)$ and $\left(x_{1}-1, x_{2}\right)$, respectively.

$$
\begin{aligned}
& \emptyset_{1} V\left(x_{1}, x_{2}+1\right)=w^{1}\left(u_{1}, x_{1}, x_{2}+1\right), \text { and } \\
& \emptyset_{1} V\left(x_{1}-1, x_{2}\right)=w^{1}\left(u_{2}, x_{1}-1, x_{2}\right) .
\end{aligned}
$$

Since V satisfies conditions C1-C6 , all possible values $\left(u_{1}\right.$, $u_{2}$ ) can take are $u_{1} \leq u_{2}$ and $(2,1)$. We make the analysis only for $u_{1}=u_{2}$, other cases can be analyzed similarly.

$$
\begin{aligned}
& u_{1}=u_{2} \\
& \emptyset_{1} V\left(x_{1}, x_{2}\right)+\emptyset_{1} V\left(x_{1}-1, x_{2}+1\right) \\
& \quad \leq w^{1}\left(u_{1}, x_{1}, x_{2}\right)+w^{1}\left(u_{1}, x_{1}-1, x_{2}+1\right) \\
& \quad \leq w^{1}\left(u_{1}, x_{1}, x_{2}+1\right)+w^{1}\left(u_{1}, x_{1}-1, x_{2}\right) \\
& \quad=\emptyset_{1} V\left(x_{1}, x_{2}+1\right)+\emptyset_{1} V\left(x_{1}-1, x_{2}\right) .
\end{aligned}
$$

\section{Under substitution operator, $\varnothing_{2}$}

Let

$$
\begin{aligned}
& w^{2}\left(1, x_{1}, x_{2}\right)=V\left(x_{1}-1, x_{1}+1\right)+c_{12} \\
& w^{2}\left(0, x_{1}, x_{2}\right)=V\left(x_{1}, x_{2}\right) \\
& w^{2}\left(-1, x_{1}, x_{2}\right)=V\left(x_{1}+1, x_{2}-1\right)+c_{21}
\end{aligned}
$$


Then $\emptyset_{2} V\left(x_{1}, x_{2}\right)=\min _{u 2} \in\{-1,0,1\} w^{2}\left(u, x_{1}, x_{2}\right)$.

We show

$\emptyset_{2} V\left(x_{1}, x_{2}+1\right)+\emptyset_{2} V\left(x_{1}-1, x_{2}\right) \geq$

$\geq \emptyset_{2} V\left(x_{1}, x_{2}\right)+\emptyset_{2} V\left(x_{1}-1, x_{2}+1\right)$.

Let $u_{1}$ and $u_{2}$ be such that

$\emptyset_{2} V\left(x_{1}, x_{2}+1\right)=w^{2}\left(u_{1}, x_{1}, x_{2}+1\right)$, and

$\emptyset_{2} V\left(x_{1}-1, x_{2}\right)=w^{2}\left(u_{2}, x_{1}-1, x_{2}\right)$.

Define

$\Delta w^{2}\left(u, x_{1}, x_{2}\right)=w^{2}\left(u, x_{1}, x_{2}+1\right)-w^{2}\left(u, x_{1}, x_{2}\right)$.

Then from condition C6, we have

$\Delta w^{2}\left(1, x_{1}, x_{2}\right) \geq \Delta_{2} w^{2}\left(0, x_{1}, x_{2}\right) \geq \Delta_{2} w^{2}\left(-1, x_{1}, x_{2}\right)$.

This implies that $w^{2}$ is supermodular with respect to $\left(u, x_{2}\right)$. Since $V$ satisfies conditions $C 1-\mathrm{C} 6$, all possible values $\left(u_{1}, u_{2}\right)$ can take are $u_{1}=u_{2}, u_{1}=0, u_{2} \in[-1,0,1]$ and $u_{2}=0, u_{1} \in\{-1$, $0,1\}$. We make the analysis only for $u_{1} \geq u_{2}$, other cases can be analyzed similarly.

$$
\begin{aligned}
& u_{1} \geq u_{2} \\
& \emptyset_{2} V\left(x_{1}, x_{2}\right)+\emptyset_{2} V\left(x_{1}-1, x_{2}+1\right) \\
& \quad \leq w^{2}\left(u_{2}, x_{1}, x_{2}\right)+w^{2}\left(u, x_{1}-1, x_{2}+1\right) \\
& \quad \leq w^{2}\left(u_{1}, x_{1}, x_{2}\right)+w^{2}\left(u_{2}, x_{1}, x_{2}+1\right)+ \\
& +w^{2}\left(u_{2}, x_{1}-1, x_{2}\right)-w^{2}\left(u_{2}, x_{1}, x_{2}\right) \\
& \quad \leq w^{2}\left(u_{1}, x_{1}, x_{2}\right)+w^{2}\left(u_{1}, x_{1}, x_{2}+1\right)+ \\
& \quad+w^{2}\left(u_{2}, x_{1}-1, x_{2}\right)-w^{2}\left(u_{1}, x_{1}, x_{2}\right) \\
& \quad=\emptyset_{2} V\left(x_{1}, x_{2}+1\right)+\emptyset_{2} V\left(x_{1}-1, x_{2}\right)
\end{aligned}
$$

The first inequality comes from the definition of $w^{2}$, second from condition $\mathrm{C} 2$, and third from supermodularity of $w^{2}$ under $\left(u, x_{2}\right)$.

\section{Under $c(x)$}

Condition C2 implies, $c\left(x_{1}, x_{2}+1\right)-\mathrm{c}\left(x_{1}, x_{2}\right) \geq c\left(x_{1}-1\right.$, $\left.x_{2}+1\right)-\mathrm{c}\left(x_{1}-1, x_{2}\right)$ should hold. It is trivial to show that $c(x)$ satisfies condition $\mathrm{C} 2$.

\section{Condition C3}

Under Replenishment operator, $\emptyset_{1}$
We need to show

$$
\begin{aligned}
& \emptyset_{1} V\left(x_{1}+1, x_{2}\right)+\emptyset_{1} V\left(x_{1}-1, x_{2}+1\right) \geq \\
& \geq \emptyset_{1} V\left(x_{1}, x_{2}\right)+\emptyset_{1} V\left(x_{1}, x_{2}+1\right)
\end{aligned}
$$

Let $u_{1}$ and $u_{2}$ be such that

$$
\begin{aligned}
& \emptyset_{1} V\left(x_{1}+1, x_{2}\right)=w^{1}\left(u_{1}, x_{1}+1, x_{2}\right), \text { and } \\
& \emptyset_{1} V\left(x_{1}-1, x_{2}+1\right)=w^{1}\left(u_{2}, x_{1}-1, x_{2}+1\right) .
\end{aligned}
$$

Since V satisfies conditions $\mathrm{C} 1-\mathrm{C} 6$, all possible values $\left(u_{1}\right.$, $u_{2}$ ) can take are $u_{1}=u_{2}=1, u_{1}=0, u_{2} \in\{0,1,2\}$ and $u_{1}=2$, $u_{2} \in\{0,1,2\}$. We make the analysis only for $\mathrm{u} 1=\mathrm{u} 2$, other cases can be analyzed similarly.

$$
\begin{aligned}
& u_{1}=u_{2} \\
& \emptyset_{1} V\left(x_{1}, x_{2}\right)+\emptyset_{1} V\left(x_{1}, x_{2}+1\right) \\
& \quad \leq w^{1}\left(u_{1}, x_{1}, x_{2}\right)+w^{1}\left(u_{1}, x_{1}, x_{2}+1\right) \\
& \quad \leq w^{1}\left(u_{1}, x_{1}+1, x_{2}\right)+w^{1}\left(u_{1}, x_{1}-1, x_{2}+1\right) \\
& \quad \leq \emptyset_{1} V\left(x_{1}+1, x_{2}\right)+\emptyset_{1} V\left(x_{1}-1, x_{2}+1\right),
\end{aligned}
$$

where the second inequality holds due to condition $\mathrm{C} 3$.

\section{Under Substitution Operator, $\emptyset_{2}$}

We show

$\emptyset_{2} V\left(x_{1}, x_{2}+1\right)+\emptyset_{2} V\left(x_{1}-1, x_{2}\right) \geq$

$\geq \emptyset_{2} V\left(x_{1}, x_{2}\right)+\emptyset_{2} V\left(x_{1}-1, x_{2}+1\right)$

Let $u_{1}$ and $u_{2}$ be such that

$\emptyset_{2} V\left(x_{1}+1, x_{2}\right)=w^{2}\left(u_{1}, x_{1}+1, x_{2}\right)$, and

$\emptyset_{2} V\left(x_{1}-1, x_{2}+1\right)=w^{2}\left(u_{2}, x_{1}-1, x_{2}+1\right)$.

Let

$\Delta_{1} w^{2}\left(u, x_{1}, x_{2}\right)=w^{2}\left(u, x_{1}+1, x_{2}\right)-w^{2}\left(u, x_{1}, x_{2}\right)$.

Due to condition $\mathrm{C} 2$, it is possible to show that

$\Delta_{1} w^{2}\left(1, x_{1}, x_{2}\right) \leq \Delta_{1} w^{2}\left(0, x_{1}, x_{2}\right) \leq \Delta_{1} w^{2}\left(-1, x_{1}, x_{2}\right)$

Hence $w^{2}$ is submodular in $\left(u, x_{1}\right)$. Since $\mathrm{V}$ satisfies conditions C1-C8, all possible values $\left(u_{1}, u_{2}\right)$ can take are $u_{1}=u_{2}, u_{1}=1$, $u_{2}=0$ and $u_{1}=0, u_{2}=-1$. We make the analysis only for $u_{1}=1$, $u_{2}=0$, other cases can be analyzed similarly.

$u_{1}=1, u_{2}=0$ 


$$
\begin{aligned}
& \emptyset_{2} V\left(x_{1}, x_{2}\right)+\emptyset_{2} V\left(x_{1}, x_{2}+1\right) \\
& \leq w^{2}\left(1, x_{1}, x_{2}\right)+w^{2}\left(0, x_{1}, x_{2}+1\right) \\
& \leq V\left(x_{1}-1, x_{2}+1\right)+c_{12}+V\left(x_{1}, x_{2}+1\right) \\
&+w^{2}\left(1, x_{1}+1, x_{2}\right)+w^{2}\left(0, x_{1}-1, x_{2}+1\right) \\
&= \emptyset_{2} V\left(x_{1}+1, x_{2}\right)+\emptyset_{2} V\left(x_{1}-1, x_{2}+1\right)
\end{aligned}
$$

Under $c(x)$

Condition C3 implies, $c\left(x_{1}+1, x_{2}\right)-c\left(x_{1}, x_{2}+1\right) \geq c\left(x_{1}\right.$, $\left.x_{2}\right)-c\left(x_{1}-1, x_{2}+1\right)$ should hold. It is trivial to show that $c(x)$ satisfies condition $\mathrm{C} 3$.

Proof.(Theorem 1) Lemma 1 shows that given $V^{t-1} \in F$, $V^{t} \in F$. This implies that $t \rightarrow \infty$, Vt satisfies conditions C1-C6.
Thus under the optimal policy there exists $S_{1}\left(x_{2}\right)$, where $S_{1}\left(x_{2}\right)$ is decreasing with $x_{2}\left(x_{1}\right)$. For one unit of increase in $x_{2}, S_{1}\left(x_{2}\right)$ decreases one unit. Furthermore, $K_{1}\left(x_{2}\right)$ and $T_{1}\left(x_{2}\right)$ are increasing in $x_{2}$.

For the policy to exist under the average reward criteria, and to have the same above-mentioned structure, one needs to show that the Markov decision process under consideration satisfies certain conditions.

The process under consideration is multi-chain, with countable state space and unbounded rewards. However, as the number of products in the inventory, or in the backorder increases, the cost rate increases linearly. This implies the number of states that the chain visits under the optimal policy must be bounded [10]. The proof of existence of an average reward policy also follows similar lines with [11].

\section{References}

[1] SHUMSKY, R. A, ZHANG, F.: Dynamic Capacity Management with Substitution Operations Research, vol. 57, No. 3, pp. 671-684, 2009

[2] GAllegO, G., KATIRCiOGLU, K., RAMACHANDRAN, B.: Semiconductor Inventory Management with Multiple Grade Parts and Downgrading, Production Planning \& Control, 17:7, pp. 689-700, 2006.

[3] ANUPINDI, R., BASSOK, Y., AKELLA, R.: Single Period Multi-Product Inventory Models with Substitution, Operations Research, vol. 47, No. 4, pp. 632-642, 1999.

[4] BALAKRISHNAN, A., GEUNES, J.: Requirements Planning with Substitutions: Exploiting Bill-of-Materials Flexibility in Production Planning. Manufacturing \& Service Operations Management, vol. 2, No. 2, pp. 166-185, 2000.

[5] IRAVANI, S. M . R., KOLFAL, B., VAN OYEN, M. P.: Process Flexibility and Inventory Flexibility via Product Substitution, accepted for publication at Flexible Services \& Manufacturing (FSM), 2012.

[6] ARCHIBALD. T. W., SASSEN, S. A. E., THOMAS, L. C.: An Optimal Policy for a Two Depot Inventory Problem with Stock Transfer, Management Science, vol. 43, No. 2, pp. 173-183 1997.

[7] AXSATER, S.: A New Decision Rule for Lateral Transshipments in Inventory Systems, Management Science, vol. 49, No. 9, pp. $1168-1179,2003$.

[8] ZHAO, H., RYAN, J. K., DESHPANDE. V.: Optimal Dynamic Production and Inventory Transshipment Policies for Multi-Location Make-to-Stock Systems, Operations Research, vol. 56, No. 2, pp. 400-410, 2008.

[9] SATIR, B., SAVASANERIL, S., SERIN. Y.: Pooling through Lateral Transshipments in Service Parts Systems, European J. of Operational Research, vol. 220, No. 2, 370-377, 2012.

[10] WEBER, R. R., STIDHAM, S. Jr.: Optimal Control of Service Rates in a Network of Queues. Advances in Applied Probability, vol. 19, pp. 202-218, 1987.

[11] HA, AY: Optimal Dynamic Scheduling Policy for a Make-to-Stock Production System Operations Research, vol. 45, No. 1, pp. 42-53, 1997. 